\title{
Response to Galbraith and Weill
}

\author{
Philip Harber · Robert Harrison · Arthur Gelb
}

Received: 29 August 2008 / Accepted: 11 May 2009 / Published online: 26 May 2009

(C) The Author(s) 2009. This article is published with open access at Springerlink.com

\section{To the Editor:}

The article of Galbraith and Weill (2009), which seriously questions whether diacetyl-induced bronchiolitis obliterans exists, also expressed doubt about the validity of the diagnoses of the two cases reported by the California Department of Health Services (Harrison 2006). We agree that the CAT scan results alone do not establish the diagnosis of bronchiolitis obliterans; however, bronchiolitis obliterans is by far the most likely diagnosis when considering the other clinical findings and pulmonary function testing showing severe nonreversible obstructive spirometric abnormalities, lung volume hyperinflation and air trapping, and maintained diffusing capacity. Similar comments apply to the biopsy of the second case, which was actually interpreted as highly consistent with bronchiolitis obliterans by an expert pathologist.

While the authors severely criticize individual components of much of the published literature, the overall weight of the scientific evidence supports an association between flavoring exposure and bronchiolitis obliterans. We concur, however, that the link to diacetyl per se is not $100 \%$ estab- lished, although the data are strongly supportive of such a causal association.

Conflict of interest Dr. Harber has agreed to testify on behalf of two of his patients if necessary. UCLA receives research and educational funding from $\mathrm{CDC} / \mathrm{NIOSH}$ for occupational health matters that may include diacetyl effects. Dr. Gelb and Dr. Harrison report no potential conflicts.

Open Access This article is distributed under the terms of the Creative Commons Attribution Noncommercial License which permits any noncommercial use, distribution, and reproduction in any medium, provided the original author(s) and source are credited.

\section{References}

Galbraith D, Weill D (2009) Popcorn lung and bronchiolitis obliterans: a critical appraisal. Int Arch Occup Environ Health 82:407-416

Harrison R, Gelb A, Harber P (2006) Food flavoring workers with bronchiolitis obliterans following exposure to diacetyl-California. California Department of Health, 15 May 2006. Available at http://www.capanet.org/pdfs/BO_cases_\%20final_5_16_06.pd

P. Harber $(\square)$

UCLA, Los Angeles, CA, USA

e-mail: pharber@mednet.ucla.edu

R. Harrison

CA Department of Health Services, Oakland, CA, USA

A. Gelb

Lakewood Medical Center and UCLA, Lakewood, CA, USA 